\title{
Carnitine palmitoyl transferase deficiency with an atypical presentation and ultrastructural mitochondrial abnormalities
}

\author{
M P CAREY,* K POULTON, C HAWKINS, $\dagger$ R P MURPHY $\dagger$ \\ From the Department of Pathology, ${ }^{*}$ Midland Centre for Neurosurgery and Neurology, Smethwick, and the \\ Department of Neurology, $\uparrow$ North Staffordshire Royal Infirmary, Stoke-on-Trent, UK
}

SUMMARY A case of carnitine palmitoyl transferase deficiency presenting in a 72 year old woman with the clinical picture of ophthalmoplegia plus other muscle weakness is reported. Histological and ultrastructural examination showed the features of a mitochondrial myopathy.

Carnitine palmitoyl transferase deficiency is a rare condition affecting only skeletal muscle clinically in most patients. ${ }^{12}$ In reported cases to date, it has been associated with a syndrome of recurrent rhabdomyolysis and myoglobulinuria, and although the enzyme is mitochondrial, no structural mitochondrial abnormalities have been reported..$^{3-9}$

We report here a case where a patient with a history of ptosis, ophthalmoplegia and proximal muscle weakness, with demonstrated ultrastructural mitochondrial abnormalities, was shown to have carnitine palmitoyl transferase deficiency on muscle biopsy.

\section{Case report}

A 72 year old lady presented with increasing weakness of her legs and arms over a period of 2 years. The weakness was accompanied by mild aching related to rest as often as exercise. During her teens and early twenties she experienced cramps in her leg muscles usually related to exercise, but never disabling. Mild ptosis had been present since her early twenties and this had worsened over the 10 years before presentation. She had been otherwise well apart from a mild Raynaud's syndrome nearly all her life and a 2 year history of angina of effort. There was no family history of myopathy.

On examination there was bilateral ptosis, weakness of abduction of both eyes with diplopia, and impaired upward gaze. Her pupils were normal. There was mild weakness of orbicularis oris, but not orbicularis oculi. Her sternomastoids were mildly wasted, but power was normal and the

Address for reprint requests: Dr MP Carey, Midland Centre for Neurosurgery and Neurology, Holly Lane, Smethwick, West Midlands, B67 7JX, UK.

Received 29 July 1986.

Accepted 23 October 1986 trapezii were normal. The remaining cranial nerves were normal. There was mild wasting and weakness of her shoulder girdle muscles, biceps and triceps, and slight weakness of the intrinsic hand muscles. Her pelvic girdle muscles were weak and there was mild wasting and weakness of quadriceps and hamstrings. Biceps and supinator reflexes were absent and tricep reflexes brisk. Knee reflexes were normal, ankle reflexes reduced and plantar responses flexor. Pes cavus and bilateral hallux valgus were noted. The remaining neurological and general examination weren normal. Investigations included ESR $(63 \mathrm{~mm} / \mathrm{h}), \mathrm{LDH}(283$ $\mathrm{mmol} / \mathrm{l}$ (normal 60-250)), CK (181 IU/1 (1-100)), free T4 (18.7 pmol/1 (11-29)), ANF and rheumatoid factor negative. Serum proteins and immunoglobulins, ECG and chest radiographs were all normal. EMG of deltoid, biceps and vastus medialis showed normal insertional activity with no abnormal activity at rest. There was an excess of small amplitude, polyphasic motor unit potentials of short or normal duration. The interference pattern was full.

Light microscopy and histochemistry There were numerous fibres showing variable degrees of atrophy and a few basophilic fibres were seen. The Gomori trichrome stain showed several red ragged fibres and the red granules in these fibres were strongly positive with NADH. The normal mosaic of fibre types was preserved, and no excess of intrafibrillary lipid was seen with the Sudan Black stain.

Electron microscopy Ultrastructural examination showed collections of abnormal mitochondria, mainly subsarcolemmal, in some fibres. (figs 1 and 2). Most of these mitochondria contained either paracrystalline inclusions or were watery with no christae. The number of inclusions varied, some mitochondria being full of them. In some they were arranged geometrically as "parking lot" inclusions. There were a few giant mitochondria in which the christae were arranged in concentric spirals, resembling a Swiss roll. The majority of fibres contained normal numbers of 1060 


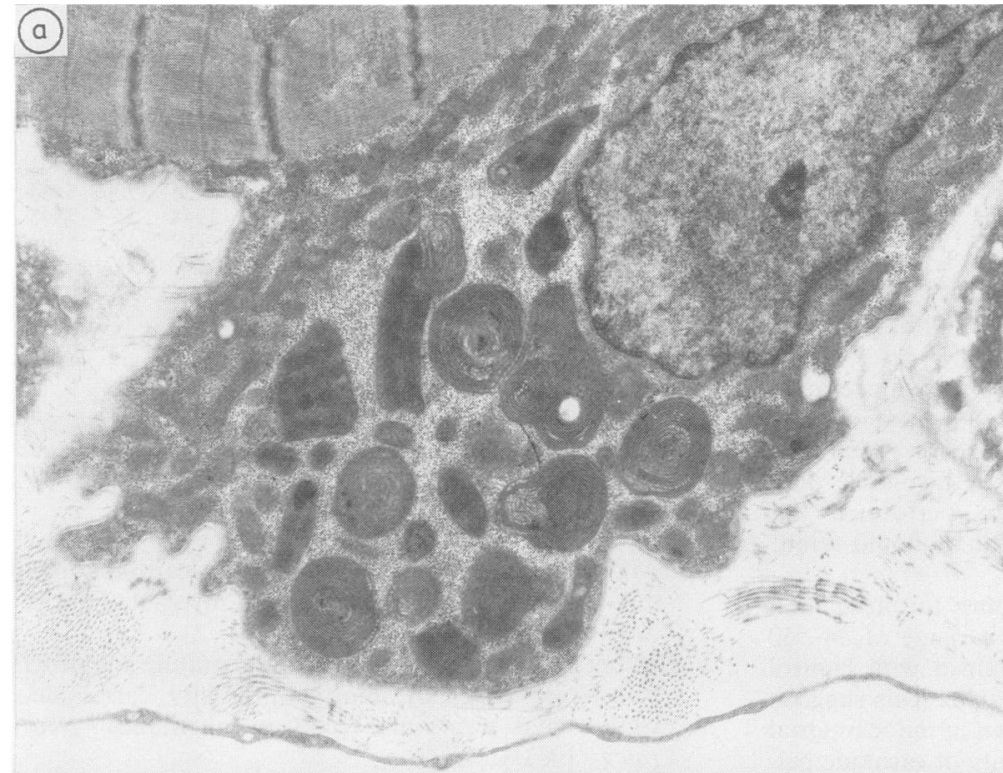

Fig 1 Subsarcolemmal collection of mitochondria including giant mitochondria with christae arranged in concentric spirals and others with dark paracrystalline inclusions $(\times 17,500)$.

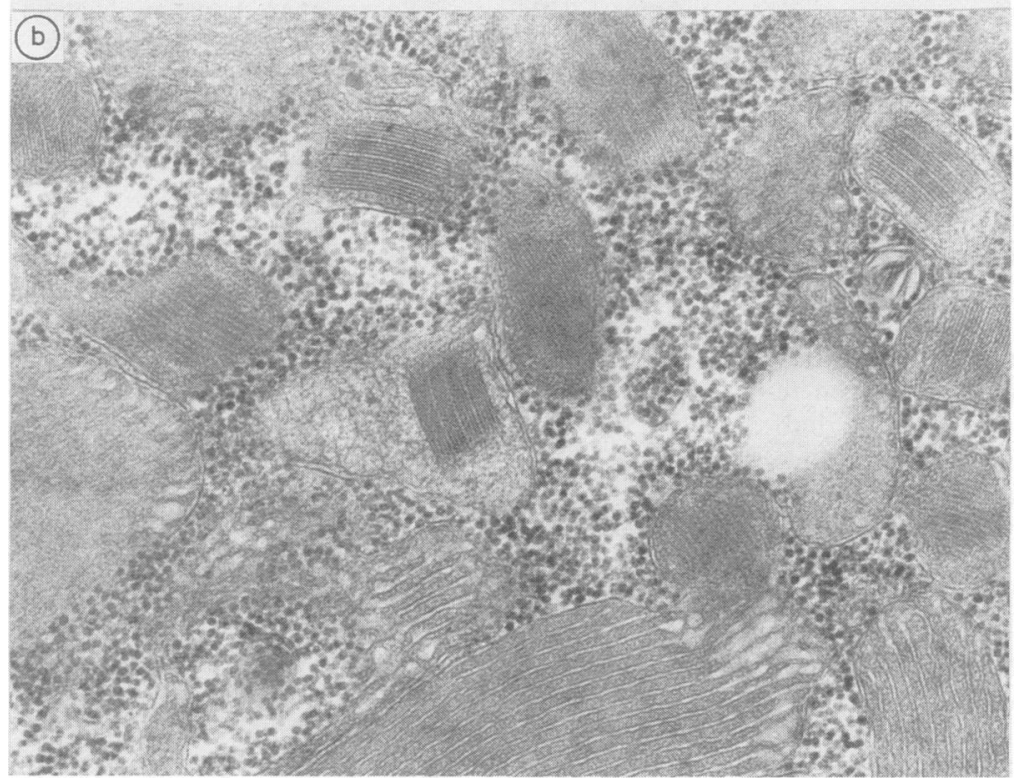

Fig 2 Collection of normal sized mitochondria containing paracrystalline inclusions and larger ones with christae in longitudinal parallel arrays $(\times 77,000)$.

morphologically normal mitochondria and no excess of intrafibrillary lipid was seen.

Biochemical methods and results Small pieces of muscle (20-30 mg) were homogenised in $500 \mu \mathrm{l}$ ice cold $10 \mathrm{mM}$ Tricine $\mathrm{pH} 7.4$ and $0.25 \mathrm{M}$ sucrose buffer containing $1 \mathrm{mM}$ EDTA. The homogenate was then sonicated in an ice/water bath for 30 minutes to solubalise the CPT 1 enzyme from the disrupted mitochondria. After centrifuging briefly $100 \mu \mathrm{l}$ aliquots of the supernatant were incubated at $37^{\circ} \mathrm{C}$ with 6 $\mathrm{mM}$ palmitoyl carnitine, $6 \mathrm{mM}$ coenzyme A, $3 \mathrm{mmol}$ diothiolthreitol in $1 \mathrm{M}$. $\mathrm{NH}_{2} \mathrm{OH}$ with $0 \cdot 1 \mathrm{M}$ MOPS pH $7 \cdot 35$ buffer for 30 minutes. The reaction was stopped with $0.2 \mathrm{ml}$ $9 \%(\mathrm{v} / \mathrm{v})$ perchloric acid and the hydroxamate in the precipitate assayed after the method of Kornberg and Prier ${ }^{10}$ and Layzer et $\mathrm{ll}^{11}$ in a Pye-Unican 1750 UV spectrophotometer at $520 \mathrm{~nm}$.

The patient had a carnitine palmitoyl transferase activity of $0.13 \mu \mathrm{mol} / \mathrm{h} / \mathrm{mg}$ compared with a mean of 4.16 $\mu \mathrm{mol} / \mathrm{h} / \mathrm{mg}$ for 45 muscle biopsy samples from patients without a diagnosis of mitochondrial myopathy. The range of results for these patients was $1 \cdot 11-8.73 \mu \mathrm{mol} / \mathrm{h} / \mathrm{mg}$. 
Table 1 Results of muscle homogenate experiments with substrate fuels

\begin{tabular}{|c|c|c|}
\hline Substrate & $\mathrm{CO}_{2}$ produced $\mathrm{nmol} / \mathrm{g} / \mathrm{h}$ & Mean values + range \\
\hline $\begin{array}{l}\text { 1.99 mM Palmitate } \\
\text { 4.78 mM Butanoate } \\
4.45 \mathrm{mM} \text { 3 Hydroxybutanoate } \\
7.07 \mathrm{mM} \text { Glucose } \\
\text { 6.98 mM Fructose } \\
5.24 \mathrm{mM} \text { Glucose-6-phosphate }\end{array}$ & $\begin{array}{r}7 \cdot 84 \\
1305 \cdot 90 \\
2262 \cdot 3 \\
439 \cdot 5 \\
46 \cdot 0 \\
29 \cdot 7\end{array}$ & 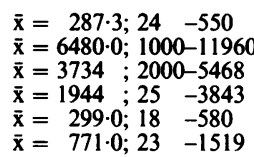 \\
\hline
\end{tabular}

Muscle was also assayed for hexokinase, phosphofructokinase, phosphorylase, phosphorylase kinase, ketohexokinase, aldolase A + B, Amylo 1,6 glucosidase, oligo 1,4-1,4 glucan transferase, acid + neutral maltase, total glycogen and glycogen structure, all of which were normal. Incubation experiments of fresh muscle fibre bundles with $\left({ }^{14} \mathrm{C}\right)$ - substrates were performed and $\left({ }^{14} \mathrm{C}\right)-\mathrm{CO}_{2}$ and $\left({ }^{14} \mathrm{C}\right)$-glycogen measured by liquid scintillation counting.

The patients muscle used palminate poorly for production of $\mathrm{CO}_{2}(3.2 \mathrm{nmol} / \mathrm{g} / \mathrm{h}$ compared with a range of $24-550$ $\mathrm{nmol} / \mathrm{g} / \mathrm{h}$ and mean $287 \mathrm{nmol} / \mathrm{g} / \mathrm{h}$ obtained with control muscle), but all other fuels normally (table). This suggests that there was not a complete breakdown in mitochondrial function and concurs with the low activity of carnitine palmitoyl transferase measured.

\section{Discussion}

Carnitine palmitoyl transferase enables long chain acyl goups to enter mitochondria and carnitine palmitoyl transferase deficiency hinders lipid entry into mitochondria. Lipid is an important source of energy for muscle metabolism, especially in prolonged exercise which cannot be sustained by glycogen metabolism for more than a few minutes. ${ }^{12}$ Carnitine palmitoyl transferase deficiency has mainly been reported in patients with a syndrome of episodic rhabdomyolysis and myoglobulinuria with no symptoms in between, presenting before middle age. ${ }^{1-37913}$ Associated respiratory failure has occurred, ${ }^{8}$ and cardiomyopathy in both adults ${ }^{6}$ and infants ${ }^{5}$ has been reported, as has malignant hyperpyrexia associated with anaesthesia. ${ }^{4}$ Our patient's clinical syndrome, however, is in marked contrast to those cases reported to date, and is more in keeping with the syndrome of ophthalmoplegia plus.

Results of light microscopy and electron microscopy in biopsies in previous cases have ranged from normal between acute episodes ${ }^{38}$ to necrosis of individual fibres and a mild excess of intrafibrillary lipid droplets. ${ }^{4-9}$ Although carnitine palmitoyl transferase is a mitochondrial enzyme, the morphological features of mitochondrial myopathies have not previously been seen in carnitine palmitoyl transferase deficiency.

In summary, we present a patient whose history and muscle biopsy findings are those of a mitochondrial myopathy, but who has carnitine palmitoyl transferase deficiency proved by biochemical assay, a condition which normally has completely different clinical and morphological features.
We thank Mr D Webb and Miss M Jeleca for their technical help.

\section{References}

1 DiMauro S, Dimauro PMM. Muscle carnitine palmitoyltransferase deficiency and myoglobulinuria. Science 1973;812:929-31.

2 Angelini C, Freddo L, Battistella P. Carnitine palmitoyl transferase deficiency: clinical variability, carrier detection and autosomal-recessive inheritance. $\mathrm{Neu}$ rology 1981;31:883-6.

3 Argor Z, DiMauro S. Recurrent exertional myalgia and myoglobulinuria due to carnitine palmitoyl transferase deficiency Isr J Med Sci 1983;19:552-4.

4 Sugiyama $S$, Wada $Y$, Morishita $H$, Nonaka T. Different ketogenic response to medium-chain triglycerides and to long-chain triglycerides in a case of muscular carnitine palmitoyl transferase deficiency. $J$ Inher Metab Dis 1982;5:233-4.

5 Normand J, Carrier H, Berthillier G, et al. Myocardiopathie primitive de l'enfant avec surcharge lipidique des fibres myocardiques et musculaires et mise, en evidence d'un deficit en enzyme palmitoylcarnitine-transferase. Arch Mal Coeur 1979:72:529-35.

6 Sacrez A, Porte A, Hindelang C, Bieth R, Merian B. Myocardiopathie avec surcharge lipidique et deficit en palmitoyl carnitine transferase (PCT) leucocytaire. Arch Mal Coeur 1982;75:1371-9.

7 Brownell AK, Severson DL, Thompson CD, Fletcher T. Cold induced rhabdomyolysis in carnitine palmitoyl transferase deficiency. Can J Neurol Sci 1979;6: $367-70$.

8 Bertormi T, Yeh Yu-Yan, Trevisan C, Stadlan E, Sabesin S, DiMauro S. Carnitine palmitoyl transferase deficiency: myoglobinuria and respiratory failure. Neurology 1980;30:263-71.

9 Werneck LC, De Almeida Boer CA, Papadimitriou A, DiMauro S. Miopatia por deficiencia de carnitinapalmitil-transferase. Arq Neuropsiquiatr 1983;41: $377-84$.

10 Kornberg A, Prier WE. Enzymatic synthesis of the coenzyme derivatives of long chain fatty acids. $J$ Biol Chem 1953;204:329-43.

11 Layzer RB, Havel RJ, Mclllroy MB. Reduced scale method for carnitine palmitoyl transferase by hydroxamate assay. Neurology 1980;30:627-33.

12 Neursholme EA, Stuart C. Regulation in Metabolism, London. John Wiley and Sons, 1973.

13 Patten BM, Wood JM, Harati Y, Hefferan P, Howell RR. Familial recurrent rhabdomyolysis due to carnitine palmitoyl transferase deficiency. Am J Med 1979;67:167-71. 